\title{
WOODS HOLE OGEANOGRAPHIC INSTITUTION
}

Woods Hole, Massachusetts

\section{Reference No. $63-38$}

The 1963 Summer Program of Theoretical Studies in

Geophysical Fluid Dynamics

\author{
by \\ George Veronis \\ Final Report \\ Submitted to the National Science Foundation \\ under Research Grant NSF GE-1518 \\ November, 1963
}


1. Description of the program:

The program in Geophysical Fluid Dynamics for the summer of 1963 was a program of work, study and discussion and was forma1ly out1ined through two courses of lectures - one on the dynamics of rotating fluids, the other, a special lecture series on astrophysics. The twenty-three participants attempted to formulate and analyze tractable problems in geophysics and astrophysics. Some of the problems are "open-ended"; that is, they were begun during the summer, progress was reported at the end of the summer and the work is being continued at the individuals' respective institutions. Other problems were of more limited scope and served to introduce some of the younger participants to areas of inquiry.

2. Participants supported by the National Science Foundation Grant:

Theodore D. Foster, M.A., Scripps Institution of Oceanography, La Jolla, California

Bernard St.Guily, Ph.D., Research Oceanographer, Laboratory of Oceanography, Museum of Natural History, Paris, France

Raymond Hide, Ph.D., Professor of Geophysics, Massachusetts Institute of Technology, Cambridge, Massachusetts

Louis N. Howard, Ph.D., Associate Professor of Mathematics, Massachusetts Institute of Technology, Cambridge, Massachusetts

Alan Ibbetson, B.Sc。, Research Assistant, Massachusetts Institute of Technology, Cambridge, Massachusetts 
Robert H. Kraichnan, Ph.D., Research-Scientist, Peterborough, New Hampshire

Paul H. LeBlond, B.Sc., Institute of Oceanography, University of British Columbia, Vancouver, Canada

Jia Ding Lin, Ph.D., Assistant Professor of Mathematics, University of Connecticut, Storrs, Connecticut

Lorenz Magaard, Ph.D., Kiel University, Kie1, Germany

Derek Moore, Ph.D., Lecturer, Department of Mathematics, Bristol University, Bristol, England

Donald.E. Osterbrock, Ph.D., Professor of Astrophysics, University of Wisconsin, Madison, Wisconsin

Peter B. Rhines, Massachusetts Institute of Technology, Cambridge, Massachusetts

Edward A. Spiegel, Ph.D., Research Scientist, Institute for Mathematica1 Sciences, New York, New.York

Robert Stein, B.Sc., Columbia University, New York, New York

Henrikus Tinkelenberg, B.Sc., Massachusetts Institute of Technology, Cambridge, Massachusetts

Alar Toomre, Ph.D., Assistant Professor of Mathematics, Massachusetts Institute of Technology, Cambridge, Massachusetts

Pierre Welander, Laborator, National Research Council, Stockholm, Sweden

Participants supported by separate funds:

Robert A. Arnoldi, Ph.D., Research Laboratories, United Aircraft Corporation, East Hartford, Connecticut

Victor Barcilon, Ph.D., Division of Applied Physics, Harvard University, Cambridge, Massachusetts 
Alan Faller, Ph.D., Woods Hole Oceanographic Institution, Woods Hole, Massachusetts

Nicholas P. Fofonoff, Ph.D., Woods Hole Oceanographic Institution, ... Woods Hole, Massachusetts

Steven Rosencrans, B.Sc. , Department of Mathematics, Massachusetts Institute of Technology, Cambridge, Massachusetts

Hans Thomas Rossby, M.Sc., Department of Geophysics, Massachusetts Institute of Technology, Cambridge, Massachusetts

Melvin E. Stern, Ph.D., Woods Hole Oceanographic Institution, Woods Hole, Massachusetts

George Veronis, Ph.D., Woods Hole Oceanographic Institution, Woods Hole, Massachusetts

\section{Course Topics for 1963:}

Dr. Derek W. Moore, the invited guest lecturer, gave a detailed report of investigations into the flow resulting from the motions of bodies through rotating fluids. His purpose was to probe deeply into one topic and thereby build a foundation for investigations into neighboring areas of study.

Dr. Donald Osterbrock presented a special lecture series on astrophysics. His discussion was meant to be an introductory survey of the more significant areas of current research in astrophysics.

A number of one-hour seminars were delivered during the program. These are 1 isted in volume three of the detailed final report. 


\section{Student 1ectures:}

At the end of the summer program eight National Science Foundation fellows and two independently-supported participants gave one-hour reports of their work. Written accounts of the work are reported in volume three.

All af the participants made a considerable effort to prepare a stimulating and original lecture.

5. Publication of the lectures and student research studies:

The notes of the summer course were taken by students assigned to each lecture. The edited version of these notes, the invited lecture series and the students' reports proved to be both a valuable record of the summer effort and a real contribution to geophysical fluid dymamics. They have been reproduced in three volumes and aré available to interested persons. 